\title{
Impacto da participação especial em campos gigantes offshore de petróleo
}

\author{
Rodrigo Mendes Gandra
}

UFF

\begin{abstract}
Resumo
Utilizando um cenário como estudo de caso, objetiva-se explorar o impacto econômico da Lei que rege a cobrança da Participação Especial (PE) pela Agência Nacional do Petróleo (ANP) sobre a decisão de investimento em projetos situados exclusivamente em campos gigantes de petróleo no Brasil. Embora este seja um exercício indutivo sem maiores pretensões, ele pode ser tomado como representativo para retratar a realidade das grandes empresas que têm em seu portfolio oportunidades de desenvolvimento de concessões com grande potencial petrolífero. Subsidiariamente, propõe-se uma alternativa ao modelo de tributação vigente.
\end{abstract}

Palavras-chave

Análise econômica de projetos, indústria de óleo e gás, tributação.

\section{Impact of special participation tax in offshore petroleum giant fields}

\begin{abstract}
The main objective of this technical study is to show the economic impact of Special Participation Tax on decisions at projects of investments at Brazilian offshore fields with high production of petroleum. An alternative estimation approach is proposed in this paper for Special Participation Tax to facilitate the economic viability of offshore projects. This technical study is only a exercise of a real situation which big companies face when it have the opportunity to develop concessions with high potential of petroleum. Above all, we propose an alternative way to calculate the assessment.
\end{abstract}

Key words

Economic analysis of projects, oil and gas industry, brazilian taxation model. 


\section{INTRODUĈ̣̃O}

No segmento de Exploração e Produção (E\&P), a construção de valor envolve a descoberta e a transformação de potenciais petrolíferos na efetiva produção comercial de volumes de óleo e de gás, viabilizando a geração de resultado econômico para continuidade e ampliação do ciclo de acumulação e geração de riqueza. De natureza extrativista e, portanto, eminentemente declinante, o segmento de E\&P

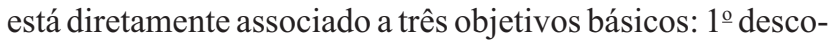
brir potencial petrolífero e incorporar reservas de petróleo; $2^{\circ}$ desenvolver a produção de reservas de petróleo; e $3^{\circ}$ produzir e comercializar óleo e gás.

O primeiro objetivo tem relação direta com a natureza extrativista e eminentemente declinante do negócio. Este objetivo permite gerar, manter e incrementar a capacidade potencial de gerar resultado econômico para viabilizar a continuidade e o crescimento das empresas de E\&P. Incluem-se aqui as atividades de exploração e avaliação, onde a viabilidade econômica e comercial do potencial petrolífero é declarada e, conseqüentemente, as reservas são incorporadas. $\mathrm{O}$ segundo objetivo está diretamente associado à realização de projetos de implantação da infra-estrutura para transformar o potencial petrolífero em efetiva produção comercial e, portanto, tem relação direta com o escopo deste trabalho. Este objetivo abrange a implantação dos projetos e a execução das obras para a construção da infraestrutura de produção. O terceiro objetivo está diretamente relacionado às atividades operacionais que geram o resultado econômico com a produção e a comercialização de óleo e gás. Este artigo concentra-se nos aspectos tributários relacionados ao $2^{\circ}$ 은 objetivo, que diz respeito a desenvolver a produção de reservas de petróleo.

No Brasil, a produção de hidrocarbonetos se dá em lâminas d'água cada vez mais profundas. Esta tendência torna os projetos offshore mais arriscados e onerosos. Além disso, parece haver (em algumas concessões) uma correlação negativa entre aumento da lâmina d'água e qualidade do óleo. A dinâmica acelerada sob a qual caminha o setor petrolífero brasileiro e o grande volume de reservas de óleo pesado em fase de desenvolvimento acaba por tornar certos aspectos da legislação verdadeiros entraves à capitalização deste potencial pelas operadoras e, conseqüentemente, pela sociedade. Segundo Álvaro Teixera (2004: 34), é uma peculiaridade do Brasil ter a maior parte do óleo pesado e produzido em águas profundas.

AParticipação Especial (PE) foi introduzida pela primeira vez na legislação brasileira como Compensação Financeira Extraordinária estabelecida pela Lei 9.478/97 (Lei do Petróleo), Decreto 2.705/98, e regulamentada pelas Portarias ANP
10/99 e 102/99. Trata-se de um pagamento adicional aos Royalties para os campos com grandes volumes de produção ou de grande rentabilidade. A aplicação da PE foi baseada em outros regimes tributários internacionais no sentido de melhor distribuir os "windfall profits", para equilibrar o fluxo de caixa entre as concessionárias e o Governo.

Segundo as Portarias ANP 10/99 e 102/99 (BARBOSA e BASTOS, 2001: 63), a PE incide sobre a receita líquida da concessão como um todo, sendo permitido deduzir da receita bruta:

- pagamento do Bônus de Assinatura (100\% no primeiro trimestre);

- pagamento dos Royalties;

- pagamento pela Retenção de Área;

- pagamento da participação ao proprietário de terra;

- pagamento de $1 \%$ do investimento em pesquisa e desenvolvimento;

- despesas pré-operacionais;

- custos de transferências;

- leasing;

- provisão de abandono;

- os investimentos na exploração (finding costs);

- os custos operacionais (operating costs); e

- depreciação dos investimentos de produção (sendo que se dá de forma acelerada para os bens nacionais).

\section{o Brasil, a produção de hidrocarbonetos profundas, tornando os projetos offshore mais arriscados e onerosos.}

Não são dedutíveis da PE o Imposto de Renda (IR), juros passivos, variações cambiais e despesas de administração (overhead costs). Contudo, o pagamento da PE é dedutível do IR.

A determinação da PE é feita mediante aplicação de alíquotas progressivas, de $10 \%, 20 \%, 30 \%, 35 \%$ e $40 \%$, em função do volume trimestral de produção, a partir de um volume limite de isenção. Para definição do volume limite de isenção, três estruturas distintas de custos foram admitidas, a saber: lavra em terra, lavra em águas rasas (até 400 $\mathrm{m}$ ) e lavra em águas profundas (acima de $400 \mathrm{~m}$ ), conforme ilustra o Gráfico 1.

Concessões gigantes em águas profundas com elevados volumes de reserva de hidrocarbonetos demandam, para seu desenvolvimento integral, a implantação de diversos módulos de produção (plataformas com linhas de produção, dutos e poços), cujas instalações ocorrem em fases. Para 
estas concessões, em particular, a atual Lei de cobrança da Participação Especial, por incidir sobre a produção conjunta de toda a concessão, faz com que a alíquota cobrada sobre os módulos de produção complementares ao primeiro (já em operação) comece sob um patamar elevado.

As empresas têm prazos delimitados para produzir, assim não podem esperar que a produção do primeiro módulo decline (esperar por alíquotas mais baixas de PE) para desenvolver um outro módulo adicional. A taxação incidente sobre a produção acumulada do campo pode acabar por inviabilizar novos projetos de E\&P. Assim, a legislação em vigor não torna atrativo o desenvolvimento de todo o potencial dos campos petrolíferos, pois os projetos adicionais (ou módulos complementares) acabam se tornando inviáveis economicamente. Em suma, neste trabalho, pretende-se:

- mostrar como a Lei pode afetar economicamente os novos projetos de E\&P;

- mostrar como a cotação do preço do petróleo influencia a arrecadação governamental;

- elucidar como estas condições podem inviabilizar certos projetos e, por conseguinte, a perda de arrecadação de tributos; e

- apresentar um cenário alternativo de incidência das alíquotas de cobrança da PE.

\section{ESTUDO DO CASO FICTÍCIO}

Este estudo de caso visa ilustrar a decisão de uma empresa denominada Standard Oil do Brasil em levar adiante, ou não, o investimento no Módulo X da concessão de Star Fish Field situado na costa marítima brasileira. Após diversos estudos efetuados, considera-se que a decisão de investimento foi levada à diretoria em maio de 2004, para que seja avaliada para aprovação. Contudo, para efeito de análise econômica, os resultados estão em valor presente de jan./2006. Foi suposto que a empresa já atua produzindo na concessão, desde 1999, com uma unidade de produção do tipo Semi Submersível (SS) própria, ligada a um Floating, Storage and Offloading (FSO) própria, e uma do tipo Floating, Production, Storage and Offloading (FPSO) afretada. Foi estimado que a produção dos módulos anteriores estaria em torno de 922 milhões

Gráfico 1: Alíquotas de Incidência da Participação Especial em Função do Volume de Reserva Drenada em Boe/ dia e do Tempo para Concessões com Lâmina d'água Acima de 400 Metros

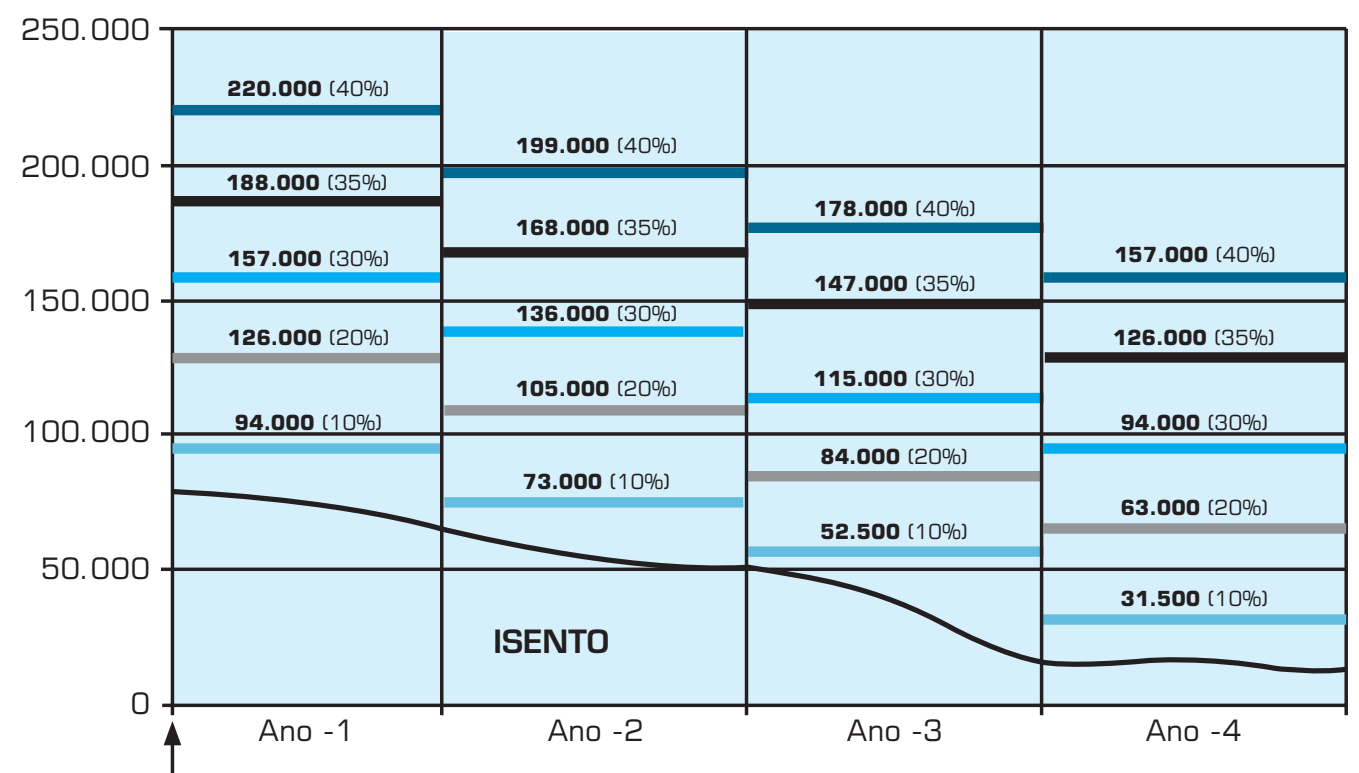

Início da Tempo após data de início da produção

produção 
de $\mathrm{Boe}^{2}$ até 2025. O escopo do Módulo X (ilustrado pela Figura 1) que é o objeto de análise de viabilidade econômica, e resume-se em:

- através do Modelo Black Oil e com a ajuda do simulador ECLIPSE $^{\text {tm }}$, estimou-se uma reserva drenada de aproximadamente 520,5 milhões de Boe entre 2008-2025 (com óleo de qualidade de $20^{\circ}$ graus API);

- profundidade de 1.255 metros de lâmina d'água;

- 10 poços produtores e 9 poços injetores de água;

- sistema de coleta da produção composto por linhas flexíveis;

- 1 Unidade Semi-Submersível (SS), denominada P-X com capacidade de processamento de 180 mil bbl de óleo por dia;

- escoamento da produção de óleo através de um oleoduto submarino de 18"; e

- escoamento da produção de gás através de 2 gasodutos submarinos de 12 ".
A composição do investimento planejado encontra-se na Tabela 1 . O planejamento das atividades do projeto foi efetuado segundo as recomendações do PMBOK 2000 e detalhado com a ajuda do software MsProject, conforme mostra o cronograma resumido no Anexo 1. Quanto ao orçamento, os autores foram a campo consultar profissionais e fornecedores de cada área técnica. A relação entre o nível de investimento e a reserva que se estima drenar (CAPEX/Boe de US\$ 4,00/Boe) está satisfatoriamente dimensionada em relação à indústria offshore já aquecida pelo aumento de demanda. Ademais, considera-se que, desde 2002, há investimento (aproximadamente US\$ 70 milhões) para aquisição de informações (i.g.: levantamento sísmico e perfuração de poços piloto) e pagamento de salário com as equipes de estudos e de projetos.

Entrando no estudo de caso, vamos chamar de Caso Base o cenário que vislumbra o sistema tributário tal como ele é hoje. Ou seja, vamos considerar que a taxa de PE incidente sobre um projeto adicional de investimento numa mesma

Figura 1. llustração do Escopo do Módulo X de Star Fish Field.

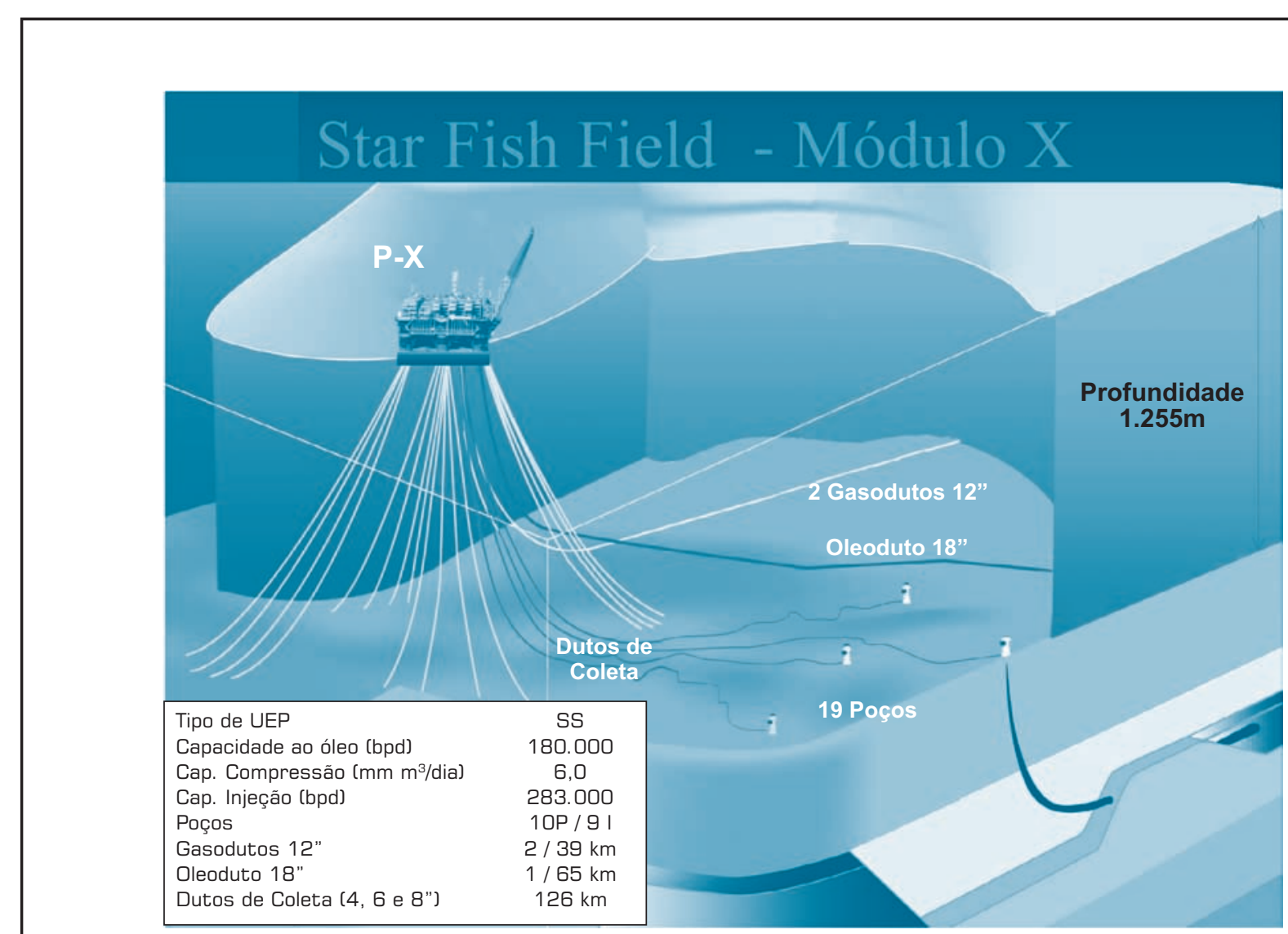


concessão depende da curva de receita líquida acumulada pelos módulos produtivos anteriores.

\section{Caso Base}

\section{Premissas}

O Caso Base descreve a situação tributária atual, em que a Participação Especial incide sobre a produção cumulativa

Tabela 1: Composição do Investimento (em US\$ milhões).

\begin{tabular}{|l|r|}
\hline Poços & 540 \\
\hline Coleta & 230 \\
\hline Escoamento & 270 \\
\hline Plataforma & 960 \\
\hline Total Sem Contingência & 2.000 \\
\hline Contingência & 100 \\
\hline Total Com Contingência & 2.100 \\
\hline
\end{tabular}

da concessão como um todo. Por critério de segurança para aprovação de projetos (atitude padrão dos investidores desta indústria), a Standard Oil do Brasil adota um Brent de Robustez de US\$ 21,00/bbl. O preço do óleo do Módulo X de Star Fish é uma função linear da cotação do preço do óleo tipo Brent. Por simplicidade, como o grau API do óleo do Módulo X de Star Fish (caracterizado como óleo pesado) é menor que o grau API do Brent, considera-se que há um spread de US\$ 4,00/bbl entre os dois tipos de óleo. O preço do óleo do Módulo X de Star Fish cotado no mercado spot quando o preço do Brent é de US\$ 21,00/bbl é: $\mathrm{P}^{\text {Mod.X }}=$ $\mathrm{P}^{\mathrm{Brent}}$ - US\$ 4,0/bbl = US\$ 17,0/bbl. As premissas utilizadas na análise econômica do Caso Base e do caso posterior estão resumidas na Tabela 2 .

Foi suposto que a Taxa Mínima de Atratividade (TMA) que desconta o fluxo de caixa do projeto é de $10 \%$ ao ano; ou seja, um baixo custo de capital para uma empresa que opera apenas no Brasil.

Quanto à depreciação, foi suposto que o investimento

Tabela 2: Premissas Básicas.

\begin{tabular}{|c|c|}
\hline Primeiro Óleo (dd/mm/a.a.) & fev./08 \\
\hline Término da Concessão (dd/mm/aa) & 31/dez./25 \\
\hline Preço do Óleo do Módulo X de Star Fish ao Brent de US\$21,00/bbl & 17,00 \\
\hline Weighted Average Cost of Capital - WACC ou TMA (\% a.a.) & $10,0 \%$ \\
\hline Início da Produção do Campo (dd/mm/a.a.) & ago./99 \\
\hline Data Base (dd/mm/a.a.) & 01/jan./06 \\
\hline Área Bloco Prod. (km²] & 884,1 \\
\hline Profundidade D’água Média ou Efetiva (m) & 1.255 \\
\hline Alíquota de Royalty do Óleo & $10,0 \%$ \\
\hline Alíquota de Royalty do Gás & $10,0 \%$ \\
\hline Alíquota do Imposto de Renda & $25,0 \%$ \\
\hline Alíquota de Contribuição Social & $9,0 \%$ \\
\hline Alíquota de PIS/PASEP & $0,65 \%$ \\
\hline Alíquota de COFINS & $7,6 \%$ \\
\hline Alíquota de CPMF & $0,38 \%$ \\
\hline Percentual da Receita Bruta para Pesquisa e Desenvolvim. (Máx. 1\%) & $1,0 \%$ \\
\hline Alíquota Média de ICMS dos Equipamentos & $19,0 \%$ \\
\hline Alíquota Média do Imposto de Produtos Industrializados (IPI) & $12,0 \%$ \\
\hline Alíquota Média do Imposto de Importação (II) & $17,0 \%$ \\
\hline Alíquota Média de ISS & $5,0 \%$ \\
\hline Alíquota de IOF & $0,0 \%$ \\
\hline Alíquota de Imposto de Renda sobre Remessa (IRRF) & $15,0 \%$ \\
\hline Inflação Brasileira (de 2007 em diante) & $5,0 \%$ \\
\hline Taxas Aduaneiras & $1,0 \%$ \\
\hline Taxa de Câmbio Empresarial (R\$/US\$) & $2,20 \%$ \\
\hline
\end{tabular}


referente à $\mathrm{P}-\mathrm{X}$ e ao gasoduto será depreciado ao longo da vida econômica do projeto (18 anos), ou seja, da sua ativação (entrada em operação - 2008) até o final do prazo de concessão (2025). Para os demais itens do investimento, foi considerada uma depreciação em 10 anos.

Cabe observar que valores residuais não foram considerados na análise, ou seja, todos os bens tiveram seus custos de investimento totalmente depreciados ao longo da vida econômica do projeto (2025), além disso, receitas não-operacionais não foram contabilizadas e o custo operacional de abandono (custo de desmobilização) foi lançado integralmente em 2026.

\section{Aspectos Tributários e a Participação Especial}

Considerando o Caso Base, ao Brent de US\$21,00/bbl, a receita nominal que o projeto obtém até o final da concessão (em 2025) é de US\$ 8.833 milhões. Deste total, o governo recolhe em impostos diretos (Government Take), em termos nominais, cerca de US\$ 3.751 milhões, ou seja, cerca de 42,5\% da receita (Tabela 3). A Participação Especial paga à ANP, que é o tributo de maior peso, totaliza US\$ 1.820 milhões e representa $20,6 \%$ da receita total e $48,5 \%$ do Government Take.

Para os cinco primeiros anos de operação do projeto, de 2008 a 2012, considerando o preço do Brent em US\$21,00/ bbl, nota-se que:

- $53,5 \%$ da receita nominal é gerada;

- 63,0\% de todo o Government Take nominal é recolhido;

- $66,8 \%$ da Participação Especial nominal é recolhida;

Os dados acima permitem constatar que a tributação concentra-se nos primeiros anos de operação deste Módulo X em questão. Estima-se que a concentração temporal da tributação nos primeiros anos de operação seja mais elevada que a concentração temporal da receita bruta. Se a tributação fosse mais diluída ao longo do tempo, certamente, melhoraria o valor presente líquido do projeto. O Gráfico 2 apresenta a relação entre a receita bruta e o Government Take em valores atualizados (jan./2006).

\section{uase todas as empresas no mundo adotam um perfil conservador, dada a incerteza natural do negócio, na} aprovação de projetos.
Conforme se pode notar pela Tabela 3, quanto maior a cotação internacional do preço do petróleo, maior a participação do governo em termos absolutos e relativos. Isto é, quanto maior a receita, maior a parcela de tributos (e, em especial, de PE).

\section{Análise Econômica}

Neste cenário, considerando o nível de tributação estruturado acima, chega-se aos resultados econômicos retratados na Tabela 4, que mostra a não-viabilidade econômica do projeto ao Brent de Robustez, uma vez que o VPL é de US\$24,21 milhões negativos. Isto significa que o projeto pode ser arriscado e talvez não seja interessante a sua efetivação. Está sendo suposto que a empresa adota apenas critérios de viabilidade econômica para aprovação de seus projetos isoladamente. É claro que a efetivação de projetos negativos ou arriscados economicamente pode ser justificada pela estratégia de gestão da carteira do portfolio da firma, que não é objeto deste trabalho. Somente ao Brent de US\$21,24/bbl o VPLEconômico é igual a zero, pois abaixo deste valor a TIR é menor que a TMA de

Tabela 3: Incidência do Government Take no Caso Base em Relação ao Aquecimento do Mercado de Petróleo (Valor Nominal).

\begin{tabular}{|c|c|c|c|c|c|c|}
\hline & \multicolumn{2}{|c|}{ Brent @21 } & \multicolumn{2}{|c|}{ Brent@25 } & \multicolumn{2}{|c|}{ Brent@30 } \\
\hline ITEM & $\begin{array}{c}\text { VALOR } \\
\text { (US\$ MILHÕES) }\end{array}$ & $\begin{array}{l}\text { PARTICIPAÇÃOO } \\
\text { NA REGEITA }\end{array}$ & $\begin{array}{c}\text { VALOR } \\
\text { (USS MILHÕES) }\end{array}$ & $\begin{array}{l}\text { PARTICIPAÇÃO } \\
\text { NA RECEITA }\end{array}$ & $\begin{array}{c}\text { VALOR } \\
\text { (US\$ MILHÕES) }\end{array}$ & $\begin{array}{l}\text { PARTICIPACCÃO } \\
\text { NA RECEITA }\end{array}$ \\
\hline Receita & $8.832,82$ & $100,00 \%$ & $10.894,77$ & $100,00 \%$ & $13.472,19$ & $100,00 \%$ \\
\hline Govermment Take & 3.750,68 & $42,46 \%$ & $4.979,37$ & $45,70 \%$ & $6.515,95$ & $48,37 \%$ \\
\hline Royalties & 911,05 & $10,31 \%$ & 1.122,35 & $10,30 \%$ & $1.386,48$ & $10,29 \%$ \\
\hline Participação Especial & $1.819,68$ & $20,60 \%$ & $2.413,28$ & $22,15 \%$ & 3. 156,36 & $23,43 \%$ \\
\hline Imposto de Renda & 728,28 & $8,25 \%$ & $1.035,90$ & $9,51 \%$ & $1.420,16$ & $10,54 \%$ \\
\hline Contribuição Social & 262,18 & $2,97 \%$ & 372,92 & $3,42 \%$ & 511,26 & $3,79 \%$ \\
\hline PIS/PASEP & 5,26 & $0,06 \%$ & 6,23 & $0,06 \%$ & 7,44 & $0,06 \%$ \\
\hline Confins & 24,23 & $0,27 \%$ & 28,68 & $0,26 \%$ & 34,25 & $0,25 \%$ \\
\hline ICMS & - & - & - & - & - & - \\
\hline
\end{tabular}


Gráfico 2: Relação entre Receita e Government Take ao Brent de Robustez de US\$ 21,00/bbl (Valor Atualizado para jan./2006).

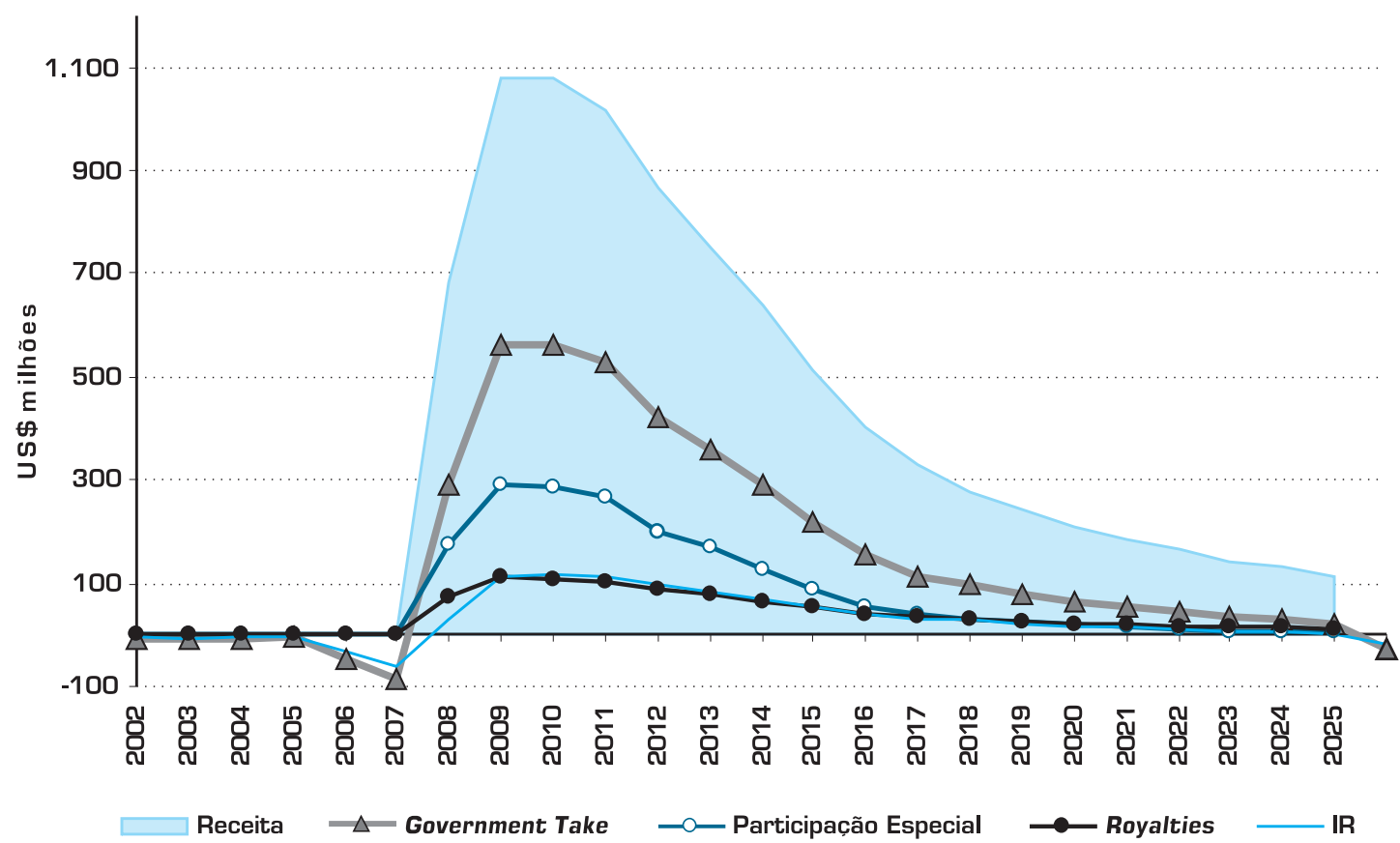

Tabela 4: Indicadores Econômicos do Caso Base.

\begin{tabular}{|c|c|c|c|}
\hline \multirow[b]{2}{*}{ INDICADORES } & \multicolumn{3}{|c|}{$\begin{array}{c}\text { MERCADO DE PETRÓLEO } \\
\text { (PREÇO DO BRENT EM USS/BBL) }\end{array}$} \\
\hline & 21,00 & 25,00 & 30,00 \\
\hline Valor Presente Líquido Econômico - VPL (milhões US\$) & $-24,21$ & 374,22 & 872,12 \\
\hline Taxa Interna de Retorno - TIR (ao ano) & $9,74 \%$ & $13,77 \%$ & $18,18 \%$ \\
\hline Lucro Unitário (US\$/BOE) & $-0,09$ & 1,40 & 3,27 \\
\hline Custo Unitário de Investimento - CUI (US\$/BOE) & 7,30 & 7,30 & 7,30 \\
\hline Custo Unitário Operacional - CUO (US\$/BOE) & 2,39 & 2,39 & 2,39 \\
\hline Custo Unitário de Tributação - CUT (US\$/BOE) & 7,40 & 9,85 & 12,92 \\
\hline Custo Unitário de Produção - CUP (US\$/BOE) & 17,09 & 19,54 & 22,61 \\
\hline Tempo de Retorno a Partir do Início da Operação & Não há ret. & 7a. $4 \mathrm{~m}$. & 5a. $2 \mathrm{~m}$. \\
\hline Receita Atualizada & $4.549,59$ & $5.610,87$ & $6.937,47$ \\
\hline Government Take Atualizado & $1.980,39$ & $2.632,38$ & $3.447,50$ \\
\hline Participação Especial Atualizada & $1.036,83$ & $1.371,87$ & $1.790,88$ \\
\hline Brent de Equilíbrio (US\$/bbl) & 21,24 & & \\
\hline
\end{tabular}


$10 \%$ ao ano, e o lucro unitário é negativo, i.e., o projeto não ofereceria retorno econômico, dada a margem de segurança imposta pela empresa. Para o tomador de decisão, o projeto apresenta uma possibilidade de oferecer uma contribuição negativa ao resto da concessão.

Visto que o projeto não se viabiliza nos critérios de conforto da empresa, vamos analisar o caso em que se propõe uma simples mudança na maneira de calcular a Participação Especial (que é justamente o tributo que tem o maior peso no Government Take em concessões gigantes).

\section{Caso Proposto - PE no Marco Zero}

\section{Premissas e Aspectos Tributários da Participação Especial}

Participação Especial no "Marco Zero" significa que o relógio para cálculo da alíquota de Participação Especial seja "zerado" no início da produção da P-X de tal forma que não seja considerada a produção passada do campo de Star Fish Field. Como a Participação Especial incide sobre a receita líquida da concessão como um todo (de modo cumulativo), quando a $\mathrm{P}-\mathrm{X}$ começar a produzir em 2008, a concessão de Star Fish já estará pagando a alíquota máxima de $40 \%$ sobre a receita líquida devido a produção dos módulos anteriores. O Gráfico 3 e o Gráfico 4 sugerem o que, na prática, está-se propondo. Na verdade, a estratégia é manter a curva de produção menos tempo sob a alíquota de máxima de $40 \%$ de PE. Ou seja, está-se propondo tributar por módulos (por unidade de produção) e não pela cumulatividade da concessão. O relógio de apuração de alíquota de $\mathrm{PE}$ só passaria a contabilizar quando a $\mathrm{P}-\mathrm{X}$ começasse a produzir em fev./2008.

\section{xistem outras soluções para 0} problema, contudo, passando

\section{a "Navalha de Occam", a proposta apresentada prima pelo pragmatismo.}

Considerando a aceitação desta nova proposta, ao Brent de US\$21,00/bbl, a receita nominal que o projeto obteria até o final da concessão (em 2025) seria de US\$ 8.833 milhões. Deste total, o governo recolheria, em termos nominais, US\$ 3.111 milhões, representando $35,2 \%$ da receita (Tabela 5). A Participação Especial paga à ANP deixaria de ser o tributo de maior peso, totalizando US\$ 814 milhões e passaria a representar $9,2 \%$ da receita bruta (ou $26,2 \%$ do

Gráfico 3: Incidência da Participação Especial sobre o Caso Base.

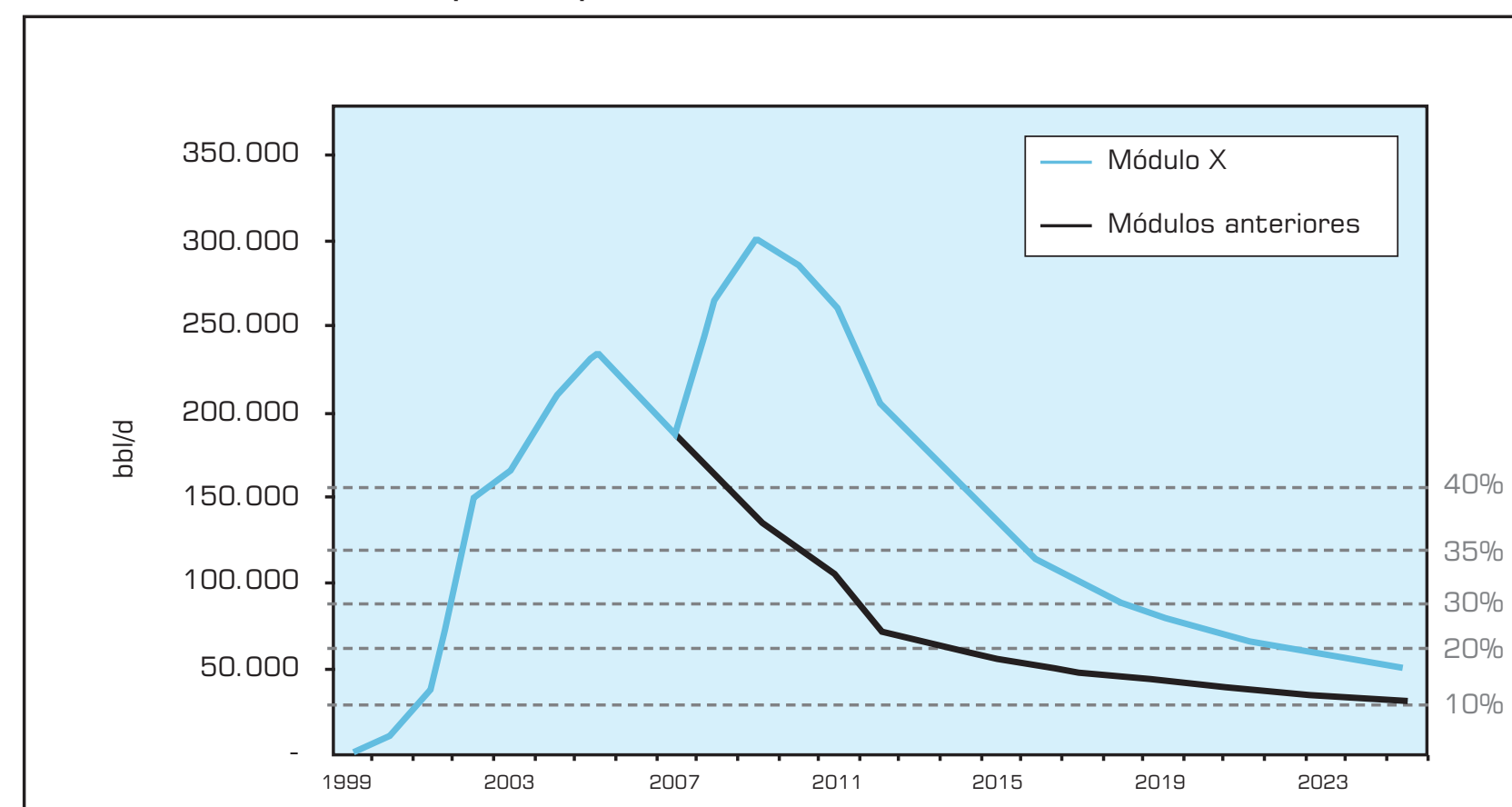


Government Take). Note que o Imposto de Renda passaria a assumir o maior peso. Ainda sim, a Participação Especial seria crescente com o crescimento da receita, contudo este crescimento seria mais suave tanto em termos absolutos, quanto em termos relativos, se comparado à situação vigente de tributação (Caso Base).
Pela Tabela 5, ainda se pode notar que, comparando com a Tabela 3 referente ao Caso Base, a PE paga seria reduzida, mas o Imposto de Renda pago (IR) e a Contribuição Social aumentariam. Ou seja, as empresas ganhariam por um lado e o governo por outro. Em termos de arrecadação de impostos diretos, o governo deixaria

Gráfico 4: Incidência da Participação Especial sobre o Caso da PE no Marco Zero.

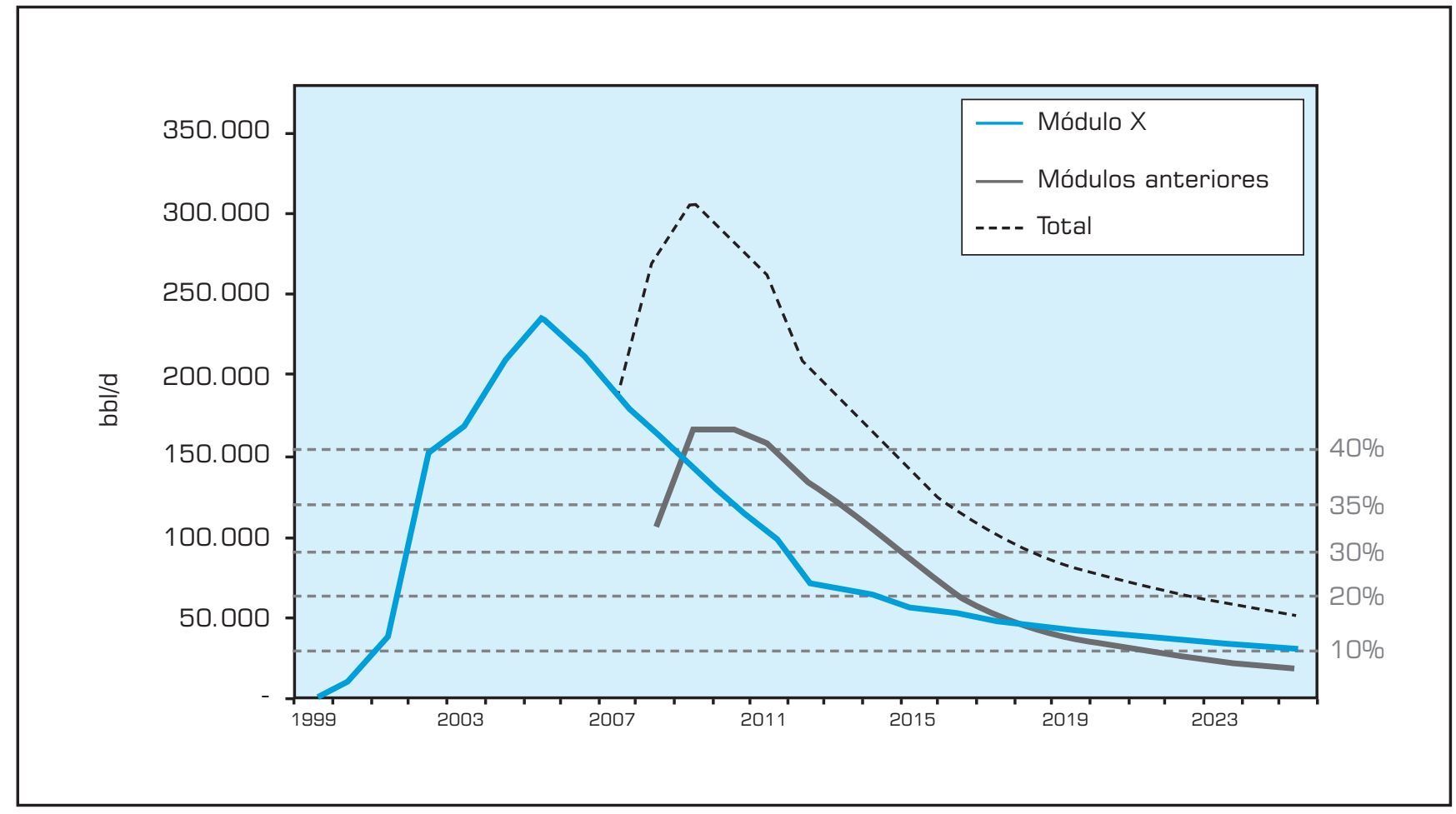

Tabela 5: Incidência do Government Take no Caso da PE Marco Zero em Relação ao Aquecimento do Mercado de Petróleo [Valor Nominal]

Brent @21

Brent @ 25

\begin{tabular}{|c|c|c|c|c|c|c|}
\hline ITEM & $\begin{array}{c}\text { VALOR } \\
\text { (US\$ MILHÕES) }\end{array}$ & $\begin{array}{l}\text { PARTICIPAÇÃOO } \\
\text { NA RECEITA }\end{array}$ & $\begin{array}{c}\text { VALOR } \\
\text { (USS MILHŌES) }\end{array}$ & $\begin{array}{l}\text { PARTICIPAÇÃO } \\
\text { NA RECEITA }\end{array}$ & $\begin{array}{c}\text { VALOR } \\
\text { (US\$ MILHÕES) }\end{array}$ & $\begin{array}{l}\text { PARTICIPAÇÃOO } \\
\text { NA RECEITA }\end{array}$ \\
\hline Receita & 8.832,82 & $100,00 \%$ & $10.894,77$ & $100,00 \%$ & $13.472,19$ & $100,00 \%$ \\
\hline Government Take & $3.110,83$ & $35,22 \%$ & 4. 124,34 & $37,86 \%$ & $5.391,22$ & $40,02 \%$ \\
\hline Royalties & 911,05 & $10,31 \%$ & 1. 122,35 & $10,30 \%$ & $1.386,48$ & $10,29 \%$ \\
\hline Participação Especial & 813,67 & $9,21 \%$ & $1.081,23$ & $9,92 \%$ & $1.415,68$ & $10,51 \%$ \\
\hline Imposto de Renda & 970,86 & $10,99 \%$ & $1.359,99$ & $12,48 \%$ & $1.846,40$ & $13,71 \%$ \\
\hline Contribuição Social & 349,50 & $3,96 \%$ & 489,59 & $4,49 \%$ & 664,70 & $4,93 \%$ \\
\hline PIS/PASEP & 5,26 & $0,06 \%$ & 6,23 & $0,06 \%$ & 7,44 & $0,06 \%$ \\
\hline Cofins & 24,23 & $0,27 \%$ & 28,68 & $0,26 \%$ & 34,25 & $0,25 \%$ \\
\hline ICMS & - & - & - & - & - & - \\
\hline
\end{tabular}


de arrecadar, considerando-se o Brent a US\$21,00/bbl, apenas US\$ 639,85 milhões.

\section{Análise Econômica}

A adoção desta proposta faria com que o projeto, ao Brent de Robustez, se tornasse viável do ponto de vista econômico (pois o VPL seria de US\$ 344,51 milhões), conforme mostra a Tabela 6. O Brent de Equilíbrio (que seria o preço médio do óleo tipo Brent no mercado que zeraria o fluxo de caixa econômico do projeto) passaria a ser US\$ $18,32 / \mathrm{bbl}$, tornando o projeto bem mais seguro economicamente.

\section{CONSIDERAC̣ÕES FINAIS}

Dado que os projetos de E\&P no Brasil estão sendo implantados cada vez mais em águas profundas (com lâmina d'água superior a 1.000 metros) e que o óleo é pesado, o "Marco Zero" de incidência da Participação Especial não deveria incidir sobre a concessão como um todo, mas sobre o início de operação de cada unidade de produção.

A adoção da proposta (PE incidente no Marco Zero) não seria a solução para todos os projetos, mas certamente ajudaria a melhorar a atratividade de alguns deles em campos gigantes em desenvolvimento, aumentando assim o aproveitamento das concessões. Não se deve pensar o quanto o governo está perdendo em termos de tributação caso uma proposta desta natureza seja negociada, mas o quanto ele deixará de arrecadar se os novos projetos não forem levados adiante. Neste sentido, ao Brent de US\$ 21,00/bbl, com a tributação atual, se a Standard Oil do Brasil não realizasse o projeto, o governo perderia U\$ $\$ 3.750,68$ milhões de arrecadação em impostos diretos. Se por acaso a ANP mudasse a metodologia de cálculo de incidência da PE, e se a Standard Oil do Brasil efetuasse o seu projeto, o governo deixaria de ganhar apenas U\$S 639,85 milhões (US\$ 3.750,68 milhões

\section{A Participação Especial não deveria incidir de operação de cada unidade de produção.}

de Government Take do Caso Base menos US\$ 3.110,83 milhões de Government Take do Caso PE Marco Zero) em impostos diretos; em valor atualizado para jan./2006 isto totaliza US\$ 349,56 milhões (conforme Tabelas 4 e 6). Em termos de arrecadação de impostos indiretos (sobre o investimento), estima-se que o governo estaria perdendo US\$ 507,20 em valor nominal. Ou seja, no total, o governo estaria perdendo US\$4.257,88 milhões em arrecadação, e a economia como um todo estaria perdendo investimentos e estaria deixando de gerar empregos de boa qualidade.

Pode-se questionar que o preço do petróleo, por conta da nova conjuntura geopolítica (invasão dos Estados Unidos ao Iraque, aumento da demanda por petróleo da China e da

Tabela 6: Indicadores Econômicos do Caso PE Marco Zero.

\begin{tabular}{|c|c|c|c|}
\hline \multirow[b]{2}{*}{ INDICADORES } & \multicolumn{3}{|c|}{$\begin{array}{c}\text { MERGADO DE PETRÓLEO } \\
\text { (PREÇO DO BRENT EM US\$/BBL) }\end{array}$} \\
\hline & 21,00 & 25,00 & 30,00 \\
\hline Valor Presente Líquido Econômico - VPL (milhões US\$) & 344,51 & 858,57 & $1.501,15$ \\
\hline Taxa Interna de Retorno - TIR (ao ano] & $13,70 \%$ & $18,56 \%$ & $23,90 \%$ \\
\hline Lucro Unitário (US\$/BOE) & 1,29 & 3,21 & 5,63 \\
\hline Custo Unitário de Investimento - CUI (US\$/BOE) & 7,30 & 7,30 & 7,30 \\
\hline Custo Unitário Operacional - CUO (US\$/BOE) & 2,39 & 2,39 & 2,39 \\
\hline Custo Unitário de Tributação - CUT (US\$/BOE) & 6,09 & 8,11 & 10,63 \\
\hline Custo Unitário de Produção - CUP [US\$/BOE] & 15,78 & 17,80 & 20,33 \\
\hline Tempo de Retorno a Partir do Início da Operação & 7a. $3 \mathrm{~m}$. & 4a. $12 \mathrm{~m}$. & 3a. $9 \mathrm{~m}$. \\
\hline Receita Atualizada & $4.549,59$ & $5.610,87$ & $6.937,47$ \\
\hline Goverment Take Atualizado & $1.630,83$ & 2. 167,18 & $2.837,62$ \\
\hline Participação Especial Atualizada & 490,83 & 650,66 & 850,45 \\
\hline Brent de Equilíbrio (US\$/bbl) & 18,32 & & \\
\hline
\end{tabular}


Índia, e do temor por crise de abastecimento) está bem acima do Brent de Robustez das firmas. Contudo, quase todas as empresas no mundo adotam um perfil conservador, dada a incerteza natural do negócio, na aprovação de projetos. Está se utilizando o critério que as empresas de óleo e gás utilizam internacionalmente. Geralmente, os investidores são conservadores na definição de suas premissas para o cálculo do fluxo de caixa quando submetem seus projetos para aprovação. Não se deve calcular um fluxo de caixa à cotação corrente do petróleo (que está acima de US $\$ 60,00 / \mathrm{bbl}$ ), pois seria muito arriscado especular que este cenário se perpetuará por mais de 20 anos, principalmente quando se está investindo acima de US\$ 2,1 bilhões. Quanto à TMA utilizada, embora seja um dado sigiloso e estratégico para as empresas (portanto,
Ministério de Minas e Energia; $10 \%$ ao Ministério do Meio Ambiente e, finalmente, $40 \%$ e $10 \%$, respectivamente, para o Estado e o Município onde ocorrer a produção em terra, ou confrontante com a plataforma continental onde se realizar a produção.

Segundo Pacheco (2003: 43-44),

“[...] das Unidades da Federação, o Estado do Rio de Janeiro é o principal beneficiário, sendo responsável, em 2002, por cerca de $99,2 \%$ do repasse aos Estados e de $39,7 \%$ do total arrecadado de participações especiais. Nota-se um rápido crescimento do montante total, se comparado com as receitas de Royalties: enquanto que estas cresceram cerca de $38,24 \%$ em 2002, as participações especiais, no mesmo período, atingiram um aumento de 45,77\%. Alguns municípios fluminenses, como Armação de Búzios e Cabo Frio, apresentaram saltos espetaculares na arrecadação, fato explicado pelas descobertas e incremento de produtividade de campos gigantes compreendidos em suas áreas, como, por exem-

de difícil acesso ao público), o trabalho considerou a taxa de uma empresa que opere apenas no Brasil. Em grandes empresas que operam em diversos países no exterior e que, portanto, diversificam seu risco, a taxa que desconta o fluxo de caixa tende a ser menor. Segundo o site na internet, Damodaran Online (http://pages.stern.nyu.edu/ adamodar/), para 148 empresas com ativos em diversos países, o setor produtor de petróleo opera com uma taxa média de 7,38\% anual. O fato desta taxa ser mais baixa que a taxa utilizada por empresas que só operam no Brasil é explicado pelo menor risco-país a que estas empresas estariam expostas. Assim, a utilização de uma TMA de 10\% anual, supondo uma empresa que só opera no Brasil, é o que se encontra, em média, no setor hoje em dia.

A Participação Especial, assim como o Bônus de Assinatura e a Retenção de Área foram introduzidos na legislação brasileira com a Lei do Petróleo. A PE incide sobre os campos com grande volume de produção ou grande rentabilidade, para que seja repassada à sociedade parte da renda oriunda das atividades petrolíferas. Os conceitos de "grande volume" e de "grande rentabilidade" estão previstos no Decreto $\mathrm{n}^{\mathrm{o}} 2.705 / 98$ e variam de acordo com o número de anos de produção, a localização da área e o volume de produção. (BARBOSA e BASTOS, 2000: 25). De conformidade com o $\S 2^{\circ}$ do art. 50 da Lei no 9.478/97, os recursos da Participação Especial são distribuídos na seguinte proporção: $40 \%$ ao plo, Marlim Sul. Tal fato leva a crer que, num curto prazo, as receitas de Royalties serão superadas pelas participações especiais, sendo que, em alguns casos, estas duas participações governamentais apresentam valores muito próximos".

Segundo a ANP (2003), o total arrecadado de Royalties pelas Unidades da Federação somou, em 2002, R\$ 1,021 bilhão, enquanto que a PE, neste mesmo período, alcançou R \$ 1,004 bilhão, um valor R\$ 17 milhões menor.

Cabe ressaltar que existem outras soluções para o problema, contudo, passando a "Navalha de Occam", a proposta apresentada prima pelo pragmatismo. $\mathrm{O}$ fato é que o problema está explícito, qual seja: segundo a simulação feita neste trabalho, considerando o cenário tributário vigente no País e o perfil conservador dos investidores deste porte, ao contrário do que se imagina, encontrar muito óleo (do tipo padrão brasileiro) numa mesma concessão torna o desenvolvimento efetivo e integral do campo inviável economicamente. Esta proposta apresentada é mais simples, por exemplo, que a proposta de mudar a metodologia de cálculo de incidência da PE, através da delimitação das concessões por blocos reservatórios. Esta última proposta esbarra na difícil tarefa (e onerosa do ponto de vista financeiro, por requerer perfuração de alguns poços) de se detectar a falta de comunicabilidade entre os blocos reservatórios. 


\section{Artigo recebido em 04/03/2005 Aprovado para publicação em 23/05/2006}

\section{- Notas}

1. Boe é a medida de volume de uma reserva em barris de óleo equivalente de óleo e gás. É aconselhável utilizar o Boe pelo critério da U.S. Securities and Exchange Commission (SEC), que é mais adequado, em termos de análise econômica, que o critério da Society of Petroleum Engineers (SPE). O critério SEC diz respeito ao volume de óleo que será economicamente viável recuperar e o critério SPE diz respeito ao volume de óleo que existe, mas que não necessariamente terá a recuperação economicamente viável. Boe $\approx 6,29$ $\times\left(1 \mathrm{~m}^{3}\right.$ de óleo $+10-3 \mathrm{~m}^{3}$ de gás $)$.

\section{neferências Bibliográficas}

AGÊNCIA NACIONAL DO PETRÓLEO (ANP). Conjuntura \& Informação, n. 10. Abr-Mai/2000.

AGÊNCIA NACIONAL DO PETRÓLEO (ANP). Anuário Estatístico Brasileiro do Petróleo e do Gás Natural 2003. Rio de Janeiro: ANP, 2003. Disponível em: http:// www.anp.gov.br.

BARBOSA, D. H. ; BASTOS, A. C. Impacto da Tributação nas Atividades de E\&P em águas profundas no Brasil. Monografia de conclusão do Curso de Especialização em Regulação para Petróleo e Gás Natural. Campinas: UNICAMP, 2000.
BARBOSA, D. H. ; BASTOS, A. C. Impacto da Tributação nas Atividades de E\&P em águas profundas no Brasil. In: Regulação em petróleo e gás natural. SULSICK, Saul B. (organizador). Campinas: Editora Komedi, 2001. p. 47-103.

GANDRA, R. M. O Impacto da "Lei Noel" em Projetos de Investimento na Indústria de Oil \& Gas: um Estudo de Caso. In Boletim INFOPETRO - Petróleo \& Gás Brasil. Ano 6, n. 1. Rio de Janeiro (RJ): Grupo de Economia da Energia do Instituto de Economia da Universidade Federal do Rio de Janeiro (IE-UFRJ), janeiro-fevereiro de 2005 (www.ie.ufrj.br/infopetro).

PACHECO, C. A. G. Aplicação e o Impacto dos Royalties do Petróleo no Desenvolvimento Econômico dos Municípios Confrontantes da Bacia de Campos. Monografia de Bacharelado em Ciências Econômicas. Rio de Janeiro, UFRJ-IE, 2003.

PROJECT MANAGEMENT INSTITUTE. PMBOK® Guide - A Guide to Project Management Body of Knowledge. Pennsylvania, USA, 2000.
SILVA, W. G. R. (Apresentação). Metodologia de Gerenciamento de Projetos do Segmento de E\&P da Petrobras. In: III Seminário Internacional do PMI-SP. São Paulo: Petrobras, agosto de 2003.

TEIXERA, A. (Entrevista). Bom senso sem fundamentalismo. Brasil Energia, n. 287, out. /2004, p. 30-34.

WOOD MACKENZIE. Deepwater Brazil Stands at the Crossroads. Latin America Upstream Insights, jun./2003.

\section{- Sobre o autor}

\section{Rodrigo Mendes Gandra}

Economista com mestrado em Ciências Econômicas pela Universidade Federal Fluminense (UFF) e analista econômico e financeiro de projetos de Investimento no segmento de E\&P da indústria de óleo e gás.

End.: Rua Cosme Velho, 318, ap. 602, bl.1.

CEP: 22241-090. Cosme Velho, Rio de Janeiro (RJ)

Tel.: (21) 2556-2619 ou 8878-3190

E-mail: rodrigo_gandra@ig.com.br 


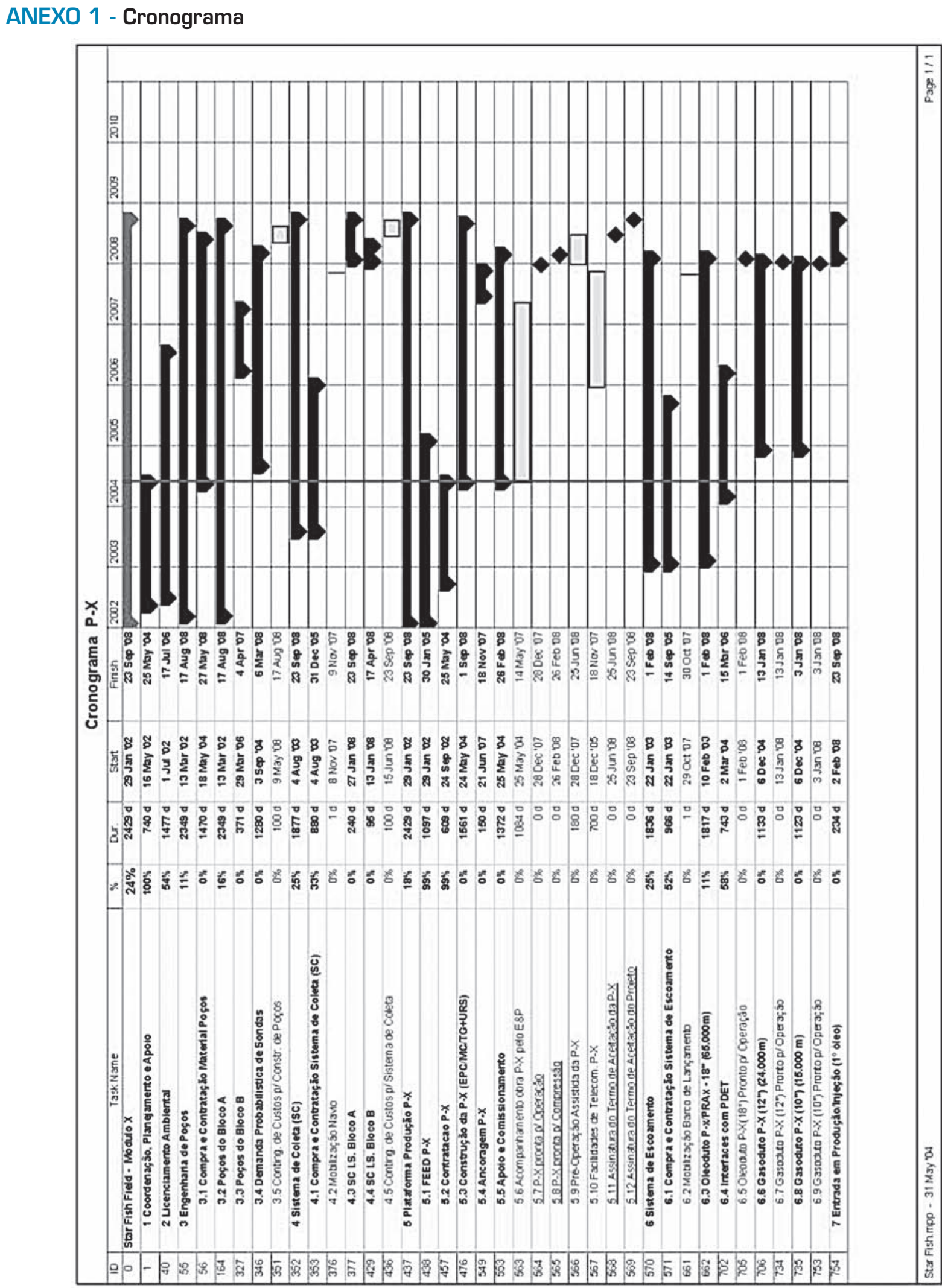

